\title{
Compassion fatigue in nursing professionals from complex care units of a Brazilian university hospital
}

\author{
Luciano Garcia Lourenção ${ }^{1, *}$, José Gustavo Monteiro Penha' ${ }^{1}$, Daniela Menezes Galvão', Francisco Rosemiro \\ Guimarães Ximenes Neto², Betânia Maria Pereira dos Santos ${ }^{3,4}$, Isabel Cristina Kowal Olm Cunha ${ }^{5}$, Jacqueline Flo- \\ res de Oliveira ${ }^{1}$, Fernando Braga dos Santos ${ }^{1}$, Márcio Andrade Borges ${ }^{1}$, Max dos Santos Afonso ${ }^{1}$, Carlos Leonardo \\ Figueiredo Cunha ${ }^{6}$, Natalia Sperli Geraldes Marin dos Santos Sasaki ${ }^{7}$, Maria de Lourdes Sperli Geraldes Santos ${ }^{7}$, \\ Neyson Pinheiro Freire ${ }^{4}$, Francielle Garcia da Silva ${ }^{1}$, Vagner Ferreira do Nascimento ${ }^{8}$, Anderson Reis de Sousa ${ }^{9}$, \\ Nuno Damácio de Carvalho Félix ${ }^{10}$, Keith Kelli Jora de Vargas ${ }^{1}$, Sidiane Teixeira Rodrigues ${ }^{1}$, Marcos Henrique \\ Dall' Aglio Foss ${ }^{7}$
}

\footnotetext{
Nursing School, Federal University of Rio Grande, Rio Grande, Rio Grande do Sul, Brazil

2 Health Sciences Center, Vale do Acaraú State University. Sobral, Ceará, Brazil

3 Technical School of Health, Federal University of Paraíba. João Pessoa, Paraíba, Brazil

4 Federal Council of Nursing. Brasília, Federal District, Brazil

5 Paulista School of Nursing, Federal University of Sao Paulo. São Paulo, São Paulo, Brazil

School of Nursing, Federal University of Pará. Belém, Pará, Brazil

School of Medicine of São José do Rio Preto. São José do Rio Preto, São Paulo, Brazil

8 Mato Grosso State University. Tangará da Serra, Mato Grosso, Brazil

Nursing School, Federal University of Bahia, Salvador, Bahia, Brazil

${ }^{10}$ Health Sciences Center, Federal University of Recôncavo da Bahia, Santo Antônio de Jesus, Bahia, Brazil

* Correspondence: lucianolourencao.enf@gmail.com
}

\begin{abstract}
The aim was to evaluate levels of compassion fatigue in nursing professionals working in complex care units of a Brazilian university hospital. A cross-sectional, descriptive, and correlational study was carried out with nursing workers from complex care units of a University Hospital. Data were collected in the second half of 2019, in the pre-pandemic period of COVID-19, using the Brazilian version of the Professional Quality of Life Scale (ProQoL-BR). A total of 146 individuals participated, including 41 (28.1\%) nurses, 92 (63.0\%) nursing technicians and 13 (8.9\%) nursing assistants. It was observed that $26.1 \%$ presented high level of compassion satisfaction. For $17.5 \%$ there was level of burnout and $49.7 \%$, medium level of burnout; and $22.0 \%$ with high and $46.1 \%$ with medium level of secondary traumatic stress. Twenty-eight $(19.2 \%)$ professionals had compassion fatigue, of which $16(57.1 \%)$ were nursing technicians. There is a high percentage of professionals with medium and high rates of burnout and secondary traumatic stress, a fact that is reinforced by the presence of compassion fatigue in almost one fifth of the studied individuals. These results highlights how much the health of these workers can be affected by living with traumatic patient experiences.
\end{abstract}

Keywords: compassion fatigue; nurse practitioners; critical care nursing; occupational health.

\section{Introduction}

In the Brazilian National Health System, nursing operates in health centers within Primary Health Care (PHC), in specialized care and hospital clinics, and various dimensions of care, including administrative, organizational, and care structures. It is essential, given that it is present in all phases of life, from birth to death [1]. In Brazil, nursing care is provided by a team composed of nurses (upper-level professionals), nursing technicians, and nursing assistants (mid-level/technical professionals) [2]. 
The nurse is responsible for supervising the nursing technicians and assistants and it is the nurse's exclusive responsibility to perform administrative and unit management activities, perform consultations, write prescription, and to provide care that requires greater technical capacity and immediate decision making, among others [2]. Mid-level professionals provide direct and continuous care, making up the front line of various health services, under the supervision of the nurse $[2,3]$.

Worldwide, the nursing team totals 27.9 million professionals [4], which comprises approximately 19.3 million nurses [5]. This indicates an increase of 4.7 million in the total contingent during the 2013-2018 period and confirms that nursing is the largest occupational group in the healthcare sector, representing about $59 \%$ of healthcare professionals in the world [4]. In Brazil, nursing represents $50 \%$ of the health workforce and has more than two million professionals, $23 \%$ nurses, $57 \%$ technicians and $20 \%$ nursing assistants $[6,7]$.

The work of these professionals has gained prominence with the advent of the new coronavirus pandemic, discovered in 2019, amidst the uncertainties regarding the treatment and cure of COVID-19 patients, and the high demand for intensive care due to the severity of the disease [8].

However, in Brazil, almost half of these health workforce is in precarious conditions of insertion in the market, with informal work contracts and many face unemployment, mostly due to lack of qualification for the position. There is a counterpoint, however, in relation to the scarcity of labor in some regions, since the significant quantity of professionals is concentrated in capitals and metropolitan regions [7].

These conditions make nursing a profession most susceptible to work overload while providing complex care to patients in the health-disease-care processes [9]. This is especially true for complex care units, such as urgency and emergency care and intensive care units (ICU), where professionals provide intensive and humanized care face exacerbated human suffering such as pain, patient loss, and family mourning. Studies increasingly show how difficult it is to manage the individual emotions experienced by professionals in this area of care [10].

The complex work practice of nursing in urgency, emergency, and ICUs involves emotional tension and physical and mental exhaustion, especially if the conditions of the work environment are unfavorable, such as places with inadequate structure, excessive noise, inadequate dimensioning or lack of personnel and material resources. Moreover, feelings related to lack of professional recognition, dissatisfaction, and poor interpersonal relationships are also related to their psychological illness [11].

Nevertheless, the environment of complex care units involves the daily coexistence of health professionals and sick people in risky situations, which requires high technical and scientific knowledge to meet their needs in a timely manner. Moreover, the constant presence of death and mourning companions, anxiety about work, rigid and often inflexible routines can increase work suffering [12-15].

The constant presence of this suffering in the work environment can trigger compassion fatigue (CF), understood as the deep involvement of the professional with situations and/or knowledge of a traumatizing event experienced, generating behaviors and negative emotions, arising from the desire to help the traumatized patient at the time of pain and suffering, generating stress. It can also be linked to personality, education, work experience, quality of personal life, satisfaction with the profession and workplace, adaptation to the environment, interpersonal relationships, and level of organization of the health service [16-18].

A study conducted in the state of Paraná, with nurses working in PHC showed that, even with high levels of compassion satisfaction, professionals show signs of fatigue [19]. In Portugal, a large percentage of nurses in an urgency and emergency service of a university hospital presented with $\mathrm{CF}$, evidenced by high levels of burnout and secondary traumatic stress [16]. In this context, it is assumed that Brazilian nursing professionals 
working in ICUs of university hospitals presented high rates of $\mathrm{CF}$, even before the COVID-19 pandemic.

Despite this, Brazilian studies on CF in nursing are scarce, especially in the hospital context, although the greater consolidation of the concept of TC in the context of health professionals is also recent. Given the above, this study aimed to evaluate the levels of CF in nursing professionals working in complex care units of a Brazilian university hospital.

\section{Materials and Methods}

\subsection{Type of Study}

We conducted a cross-sectional, descriptive, and correlational study in the second semester of 2019, during the pre-pandemic period of COVID-19, with nursing professionals from complex care units of a university hospital in the south of Brazil.

Hospital Universitário Dr. Miguel Riet Corrêa Jr. is linked to the Federal University of Rio Grande and is located in the city of Rio Grande, in the state of Rio Grande do Sul. It is a medium-sized hospital and a reference in many medical specialties. It has a total of 221 beds distributed in the areas of intensive care (adult, neonatal, and pediatric), surgical and clinical specialties, and obstetrics and pediatrics. The nursing staff of the hospital is composed of 146 nurses, 218 nursing technicians, and 133 nursing assistants [20].

\subsection{Sample and Participants}

The sample consisted of 146 nursing professionals, consisting 41 nurses, 92 nursing technicians, and 13 nursing assistants, who work in the Emergency Room and in three ICUs of the hospital (adult ICU, pediatric ICU and neonatal ICU). The inclusion criterion was to have worked in the hospital for at least six months.

\subsection{Procedures, Measurements, Variables and Outcome}

For data collection we using two self-report instruments, including a questionnaire prepared by the researchers, containing sociodemographic variables (professional category, gender, age, marital status, and education) and professional variables (work sector, type of activity, work shift, family income, time of performance in the hospital, whether it has another paid activity) and the Professional Quality of Life Scale - BR (ProQoL-BR), validated for Brazil by Lago and Codo [21]. The ProQoL-BR is composed of 30 questions related to the experience of the professional with compassion for the people they help. The answers are Likert-type on a scale of 0 to 5 , where $0=$ never, $1=$ rarely, $2=$ sometimes, 3 = frequently, 4 = very frequently, and $5=$ almost always.

ProQoL-BR items are divided into three subscales, which correspond to the dimensions of quality of work life. Each dimension comprises 10 items, which assess: compassion satisfaction (CS) - items 3, 6, 12, 16, 18, 20, 22, 24, 27, 30; burnout (BO) - items 1, 4, 8, $10,15,17,19,21,26,29$; and secondary traumatic stress (ETS) - items 2, 5, 7, 9, 11, 13, 14, $23,25,28$. The total value of each subscale is obtained by summing the scores of each of the 10 corresponding items, and the values of items 1, 4, 15, 17, and 29 should be reversed. Compassion fatigue results from high burnout and high secondary traumatic stress [22].

\subsection{Statistical Analysis}

The data were stored in a Microsoft Excel® spreadsheet and analyzed with the SPSS $®$ program, version 23.0. Descriptive statistics (frequencies, mean, median, minimum and maximum values, and standard deviation) and inferential statistics (Pearson's correlation coefficient, $\mathrm{t}$-test and Mann-Whitney test) were utilized while considering the significance level of $5 \%(p \leq 0.05)$. The correlation between the variables was considered weak for $r$ values up to 0.30 , moderate for values between 0.40 and 0.60 , and strong for values greater than 0.70 [23]. The Kolmogorov-Smirnov test was applied to verify normality in data distribution. 
The calculation of the cutoff points of the ProQol-BR scale followed the guidelines of The Concise ProQoL Manual [22], transforming the primary values of the subscales of compassion satisfaction, burnout, and secondary traumatic stress into Z scores and these into $\mathrm{T}$ scores. Converting the primary values to $M=50$ and $S D=10$ allows comparison between the values of the three dimensions and with the literature.

\subsection{Ethical Considerations}

Ethical approval regarding this study was obtained from the institutional ethics committee (decision: 2,896,620 - September 15, 2018; CAAE: 93476218.2.0000.5324). Participants were only included after informed consent had been obtained from them. All procedures performed in this study were compatible with the ethical standards of the institutional research committee and with those of the Declaration of Helsinki and its comparable ethical standards.

\section{Results}

A total of 146 nursing professionals participated in the study, including $28.1 \%$ nurses, $63.0 \%$ nursing technicians, and $8.9 \%$ nursing assistants. Their age ranged from 23 to 62 years, with a mean of 37.6 years (95\% CI: 36.2 to 38.9 years). Regarding the place of work, $56.2 \%$ worked in the urgent care and emergency sector, $8.9 \%$ in the adult ICU, $28.1 \%$ worked in the neonatal ICU, and $9.6 \%$ in the pediatric ICU. There was a predominance of female professionals $(80.8 \%)$, those that were married $(55.5 \%)$, with complete college education (47.9\%), engaged in developing assistive activities (82.9\%), working the night shift $(41.8 \%)$, with family income from two to five minimum wages $(60.3 \%)$, and were not engaged in other paid activities (87.0\%) (Table 1).

Table 1. Sociodemographic and professional characteristics of nursing workers.

\begin{tabular}{lrr}
\hline \multicolumn{1}{c}{ Variables } & \multicolumn{1}{c}{$\boldsymbol{n}$} & \multicolumn{1}{c}{$\%$} \\
\hline Professional Category & & \\
Nurse & 41 & 28.1 \\
Nursing Technician & 13 & 8.9 \\
Nursing Auxiliary & 92 & 63.0 \\
Sex & & \\
Male & 27 & 18.5 \\
Female & 118 & 80.8 \\
No answer & 1 & 0.7 \\
Age Group (years) & & \\
18 to 39 & 86 & 58.9 \\
40 to 59 & 45 & 30.8 \\
60 or more & 2 & 1.4 \\
No answer & 13 & 8.9 \\
Education & & \\
Elementary School & 23 & 15.8 \\
High School & 52 & 35.6 \\
Higher Education Complete & 70 & 47.9 \\
No answer & 1 & 0.7 \\
Civil Status & & \\
Married & 98 & 67.1 \\
Single & 37 & 25.3 \\
\hline
\end{tabular}




\begin{tabular}{|c|c|c|}
\hline Separated & 10 & 6.8 \\
\hline Widower & 1 & 0.7 \\
\hline \multicolumn{3}{|c|}{ Family Income (minimum wages*) } \\
\hline From two to five & 88 & 60.3 \\
\hline From six to 10 & 46 & 31.5 \\
\hline More than 10 & 10 & 6.8 \\
\hline No answer & 2 & 1.4 \\
\hline \multicolumn{3}{|l|}{ Work Sector } \\
\hline Emergency Care Service & 81 & 55.5 \\
\hline Adult ICU & 13 & 8.9 \\
\hline Neonatal ICU & 39 & 26.7 \\
\hline Pediatric ICU & 13 & 8.9 \\
\hline \multicolumn{3}{|l|}{ Type of Activity } \\
\hline Assistive & 121 & 82.9 \\
\hline Administrative and Assistive & 21 & 14.4 \\
\hline No answer & 4 & 2.7 \\
\hline \multicolumn{3}{|l|}{ Shift Work } \\
\hline Morning (six hours) & 43 & 29.5 \\
\hline Afternoon (six hours) & 40 & 27.4 \\
\hline Night shift (12 x 36 hours) & 61 & 41.8 \\
\hline Full Daytime (eight hours) & 2 & 1.4 \\
\hline \multicolumn{3}{|l|}{ Time of work in the hospital } \\
\hline Up to two years & 62 & 42.5 \\
\hline$>$ two and $\leq$ five years & 27 & 18.5 \\
\hline$>$ five and $\leq 10$ years & 21 & 14.4 \\
\hline Over 10 years & 31 & 21.2 \\
\hline \multicolumn{3}{|l|}{ Practice physical activity } \\
\hline Yes & 59 & 40.4 \\
\hline No & 86 & 58.9 \\
\hline No answer & 1 & 0.7 \\
\hline \multicolumn{3}{|l|}{ Has another paid activity } \\
\hline Yes & 17 & 11.6 \\
\hline No & 127 & 87.0 \\
\hline No answer & 2 & 1.4 \\
\hline
\end{tabular}

Cronbach's alpha coefficient values obtained for compassion satisfaction $(0.81)$, burnout (0.79) and secondary traumatic stress (0.78) subscales can be found in Table 2 . In the general evaluation of the dimensions of professional quality of life, it was observed that nursing professionals from complex care units presented scores compatible with a high level of compassion satisfaction (44.1) and low average scores for burnout (19.3) and for secondary traumatic stress (16.0).

Correlation analysis among the dimensions of quality of work life revealed a negative and weak correlation between compassion satisfaction and secondary traumatic 
stress $(r=-0.316 ; p<0.001)$; negative and moderate correlation between compassion satisfaction and burnout $(r=-0.491 ; p<0.001)$, and positive and moderate correlation between burnout and traumatic stress $(r=0.668 ; p<0.001)$ (Table 2).

Table 2. Analysis of the dimensions of professional quality of life of nursing workers.

\begin{tabular}{|c|c|c|c|c|c|c|c|}
\hline $\begin{array}{c}\text { Dimensions of the } \\
\text { ProQol-BR* }\end{array}$ & $\begin{array}{c}\text { Alfa de } \\
\text { Cronbach }\end{array}$ & Min & Max & Mean & $\mathrm{SD}^{* *}$ & $\begin{array}{l}\text { Compassion } \\
\text { Satisfaction }\end{array}$ & Burnout \\
\hline Compassion satisfaction & 0.81 & 26.0 & 50.0 & 44.1 & 4.6 & & \\
\hline Burnout & 0.79 & 6.0 & 38.0 & 19.3 & 5.9 & $\begin{array}{c}-0.491 \\
(<0.001)^{+}\end{array}$ & \\
\hline $\begin{array}{l}\text { Secondary } \\
\text { stress }\end{array}$ & 0.78 & 4.0 & 39.0 & 16.0 & 7.1 & $\begin{array}{c}-0.316 \\
(<0.001)^{+}\end{array}$ & $\begin{array}{c}0.668 \\
(<0.001)^{+}\end{array}$ \\
\hline
\end{tabular}

As shown in Table 3, the analysis of the dimensions of professional quality of life in relation to the sociodemographic characteristics showed that the mean score for burnout was significantly higher among nurses $(p=0.008)$, workers with higher education $(p=0.012)$, and those who perform care and administrative activities $(p=0.018)$; professionals who work in the morning had a significantly higher score for secondary traumatic stress $(p=0.033)$.

Table 3. Analysis of the dimensions of professional quality of life in relation to the sociodemographic and professional characteristics of nursing workers.

\begin{tabular}{|c|c|c|c|}
\hline \multirow{3}{*}{ Variables } & \multicolumn{2}{|c|}{ Dimensions of the ProQol-BR* } & \multirow{3}{*}{$p$ value } \\
\hline & \multirow{2}{*}{$\begin{array}{c}\text { Burnout } \\
\text { Mean (SD) }\end{array}$} & \multirow{2}{*}{$\begin{array}{c}\text { Secondary traumatic } \\
\text { stress } \\
\text { Mean }(S D)\end{array}$} & \\
\hline & & & \\
\hline \multicolumn{4}{|l|}{ Professional Category } \\
\hline Nurse & $21.6(5.2)$ & & \multirow{3}{*}{$0.008^{+}$} \\
\hline Nursing Technician & $20.2(8.1)$ & & \\
\hline Nursing Auxiliary & $18.1(5.6)$ & & \\
\hline \multicolumn{4}{|l|}{ Education } \\
\hline Elementary School & $16.3(5.3)$ & & \multirow{3}{*}{$0.012^{+}$} \\
\hline High School & $18.7(6.0)$ & & \\
\hline Higher Education Complete & $20.5(5.8)$ & & \\
\hline \multicolumn{4}{|l|}{ Shift Work } \\
\hline Morning (six hours) & & $18.3(7.5)$ & \multirow{4}{*}{$0.033^{+}$} \\
\hline Afternoon (six hours) & & $15.1(6.5)$ & \\
\hline Night shift (12 x 36 hours) & & $15.0(6.9)$ & \\
\hline Full Daytime (eight hours) & & $16.5(3.5)$ & \\
\hline \multicolumn{4}{|l|}{ Type of Activity } \\
\hline Assistive & $18.9(6.1)$ & & \multirow{2}{*}{$0.018^{++}$} \\
\hline Administrative and Assistive & $21.5(3.8)$ & & \\
\hline
\end{tabular}

${ }^{*}$ ProQol-BR = Professional Quality of Life Scale $-B R .{ }^{+}$ANOVA. ${ }^{+}$Student's t-test. 
Considering the percentiles as cutoff points, it was found that $26.1 \%$ of the professionals presented high level of compassion satisfaction, $17.5 \%$ high level of burnout, and $22.0 \%$ with high level of secondary traumatic stress. While $26.1 \%$ of the professionals presented low level of compassion satisfaction, $49.7 \%$ medium level of burnout, and $46.1 \%$ with medium level of secondary traumatic stress (Table 4 ).

Table 4. ProQol-BR cut-off points and frequencies of nursing workers by classification level of the dimensions of professional quality of life.

\begin{tabular}{lcccccc}
\hline $\begin{array}{l}\text { Dimensions of the } \\
\text { ProQol-BR }\end{array}$ & \multicolumn{2}{c}{$\begin{array}{c}\text { Cutoff Points - Per- } \\
\text { centiles (t scores) }\end{array}$} & \multicolumn{3}{c}{ Classification Levels } \\
\cline { 2 - 7 } & 25 & 50 & 75 & Low & Medium & High \\
\hline $\begin{array}{l}\text { Compassion satisfac- } \\
\text { tion }\end{array}$ & 43.3 & 51.9 & 58.4 & $35(26.1)$ & $64(47.8)$ & $35(26.1)$ \\
$\begin{array}{l}\text { Burnout } \\
\text { Secondary traumatic }\end{array}$ & 42.8 & 49.5 & 54.6 & $45(32.8)$ & $68(49.7)$ & $24(17.5)$ \\
stress & 41.8 & 48.5 & 57.0 & $45(31.9)$ & $65(46.1)$ & $31(22.0)$ \\
\hline
\end{tabular}

* ProQol-BR = Professional Quality of Life Scale $-B R$.

It was observed that $19.2 \%$ professionals had CF, of which $57.1 \%$ were nursing technicians. Regarding socio-demographic and professional characteristics, it was found that most professionals with CS were female $(82.1 \%)$, aged between 18 and 39 years $(60.7 \%)$, married $(71.4 \%)$, had completed college education $(50.0 \%)$, worked in the emergency department (50, had less than two years of experience $(35.7 \%)$ ), worked at night $(42.9 \%)$, performed assistive activities $(85.7 \%)$, had an income of two to five minimum wages $(64.3 \%)$, were not engaged in other paid activities $(89.3 \%)$, and did not practice any physical activity (53.6\%).

\section{Discussion}

The profile of the workers in this study portrays the profile of nursing in Brazil, a category composed predominantly of mid-level professionals (nursing assistants and technicians), female, aged between 26 and 40 years [7].

The reliability of the subscales was evaluated using Cronbach's alpha coefficient, considering values between 0.60 and 0.70 as weak internal consistency; between 0.70 and 0.80 as reasonable internal consistency; between 0.80 and 0.90 as good internal consistency; and greater than 0.90 as very good internal consistency [24]. The results of analysis for the dimensions of the ProQol-BR scale demonstrated values very close to those obtained in the study of factor validity and internal consistency of the ProQol-BR scale (0.81 for CS, 0.83 for BO, and 0.76 for ETS, respectively) [21,24].

The scores obtained by professionals from complex care units are similar to those presented by other studies [16,25] and demonstrate that these professionals have positive feelings about their ability to be effective at work and have high satisfaction in developing their work activities, contributing to the team, and the work environment [21,22].

The significantly higher levels of burnout among nurses, upper level workers who work in assistance and management, confirm that they perform managerial activities that have a higher risk of presenting burnout due to the higher workload, as they accumulate assistance activities with administrative ones imposing greater responsibilities related to people management and the conflicts present in the work environment [26,27].

The higher level of secondary traumatic stress among professionals who work in the morning period can be associated to the stress generated by task distribution, because 
this period commonly has a higher concentration of procedures, such as showering, administration of medications, change of dressings, medical visits, and adjacent interventions of other professionals, such as physical therapists. The last can lead to insufficient time for nursing professionals to work, leading to stress, and compromising their health and quality of life [28-30].

The constant presence of burnout and secondary traumatic stress in the work environment can trigger compassion fatigue (CF), defined as a state of fatigue and psychic exhaustion in dealing with others' suffering, which may be related to decreased general well-being, inability to cope with the exposed conditions, and intense absorption of the patients' suffering $[17,18]$.

Nursing professionals working in complex care environments may develop CF, secondary traumatic stress, and burnout, requiring the implementation of therapeutic interventions geared toward the health and resilience of these workers [16,18,31,32]. Many neonatal ICU nurses report that the CF is high and this requires urgent emotional health intervention. The CF points to a mental and physical illness resulting from chronic stress at work and subjective experiences suffered in a unique way, by each professional, in the course of treatment of the patients they assist [33].

The mean values resulting from the cutoff points for the dimensions of the ProQol-BR scale were similar to those found in other Brazilian [24] and non-Brazilian studies [16,35-37]. There is a high percentage of professionals with medium and high indices of burnout and secondary traumatic stress, which are indicative of CF, corroborating the national and international literature, which indicates the nursing profession to be risk category for CF [16,18,25-27,30,35,36].

In this context, it is highlighted that it is common for nurses to provide care to critically ill patients and develop feelings of compassion, because they see in their patients desires and sufferings that may be common to a family member or to themselves $[10,16]$. However, when the feeling of compassion interferes with personal and emotional life and becomes a pathological psychic suffering, it can interfere with professional conduct and decision making, compromising the quality of care [17].

If it is not identified and treated in time, CF can harm the assistance provided to users of health services, since the professionals can develop defense mechanisms, such as the denial of the importance of the person, detachment, denial of feelings, postponing decisions, and the reduction of the sense of professional responsibility that, consequently, will cause iatrogenesis [37].

A study conducted with health professionals in the ICU of four university hospitals in São Paulo showed the existence of an imbalance in the quality of professional life (QoL) indicating suffering of professionals. The imbalance occurs when negative experiences (such as burnout and secondary traumatic stress, which are related to $\mathrm{CF}$ ) prevail over positive experiences (such as satisfaction by compassion). This might be either due to emotional and affective involvement with patients' suffering and pain or because of emotional exhaustion and frustration related to work and its conditions [12].

Complex care units such as ICU, ER, and oncology seem to be more prone to the emergence of CF due to patients presenting a higher risk of complications and deaths and due to the demand for specific professional skills and quick responses. Scores compatible with the presence of CF among professionals who work in these sectors, associated with lower scores of compassion satisfaction, have a direct relationship with the development of depression, anxiety and stress [38].

However, the work in other less critical health sectors, such as PHC units, can also propitiate the emergence of $\mathrm{CF}$, as demonstrated in studies conducted in Brazil [19] and Spain [39]. These studies detected high levels of CF and burnout and showed that even with high levels of compassion satisfaction, professionals show signs of fatigue [19,39].

The literature also indicates that nurses with little experience in ICU tend to present higher scores of CF, being considered high risk for psychological illness. In addition, workers who remain in these environments for periods longer than 40 hours per week 
also present a higher risk for the development of CF [40]. Although this study showed a low percentage of workers with other jobs, it is common that Brazilian nursing professionals have more than one job and therefore, work more than 60 hours per week, which can increase the risk of developing CF, especially when they work in critical sectors, such as the ICU.

Another aspect that can contribute to the presence of high levels of CF is young age (20 to 35 years old), which is indicated as being more susceptible to develop CF [40] and, as shown in this study, more than $50 \%$ of professionals were younger than 39 years old.

It is noteworthy that there is an important relationship between the development of $\mathrm{CF}$, gender, and work environment. Although female professionals, predominant in Brazil, tend to have better levels of compassion satisfaction compared to males, the work environment/sector significantly impacts the secondary stress syndrome, which compromises the problem-solving and social support-seeking abilities of professionals, favoring the development of CF [20]. This aspect corroborates the results presented by the Brazilian professionals evaluated in this study and justifies the levels of CF described in the literature among nursing workers in complex care units, since there is a great emotional burden on these professionals in relation to other nursing specialties [30,41].

The cross-sectional design of this study does not make it possible to establish cause and effect relationships. However, its results should be appreciated carefully, since the results point to the presence of professionals with CF in complex care units before the advent of the COVID-19 pandemic, which generated work overload and intensified their stress and suffering. Another limitation of the study is the inclusion of professionals from a single hospital, limiting the generalizability of results. However, the study stands out by identifying the levels of HR in professionals of complex care units in a Brazilian university hospital in the pre-pandemic period, allowing future evaluation of the impact of COVID-19 on the mental health of these workers, due to living with the suffering and high number of deaths of people severely affected by the disease.

\section{Conclusions}

Nursing professionals working in complex care units of a university hospital in southern Brazil, showed high levels of compassion satisfaction and low levels of burnout and secondary traumatic stress. However, when considering the cutoff points, it was observed that there is a high percentage of professionals with medium to high rates of burnout and secondary traumatic stress, which are directly related to compassion fatigue, a fact that is reinforced by the presence of CF in almost one fifth of the professionals studied. These results highlight how much the health of nursing professionals can be affected by living with traumatic experiences of their patients.

This study emphasizes the need to develop new research on this topic, to evaluate the impact of the COVID-19 pandemic on the CF levels of nursing professionals who worked on the front line during the pandemic, as well as to analyze therapeutic possibilities once the CF is detected. In addition, it is essential to include this content in continuing education to enable professionals to identify early symptoms of CF and seek help as soon as possible, avoiding sick leave and improving their health conditions, well-being, and quality of life.

Author Contributions: Conceptualization, L.G.L. and J.G.M.P.; methodology, L.G.L.; software, L.G.L.; formal analysis, L.G.L.; investigation, L.G.L., J.G.M.P., D.M.G. and K.K.J.V.; resources, L.G.L., J.G.M.P., and D.M.G.; data curation, L.G.L. and J.G.M.P.; writing - original draft preparation, L.G.L., J.G.M.P. and D.M.G.; writing-review and editing, F.R.G.X.N., B.M.P.S., I.C.K.O.C., J.F.O., F.B.S., M.A.B., M.S.A., C.L.F.C., N.S.G.M.S.S., M.L.S.G.S., N.P.F., F.G.S., V.F.N., A.R.S., N.D.C.F., K.K.J.V., S.T.R. and M.H.D.F; visualization, L.G.L., J.G.M.P., D.M.G., K.K.J.V., F.R.G.X.N., B.M.P.S., I.C.K.O.C., J.F.O., F.B.S., M.A.B., M.S.A., C.L.F.C., N.S.G.M.S.S., M.L.S.G.S., N.P.F., F.G.S., V.F.N., A.R.S., N.D.C.F., K.K.J.V., S.T.R. and M.H.D.F; validation, L.G.L., J.G.M.P., D.M.G., F.R.G.X.N., B.M.P.S., I.C.K.O.C., J.F.O., F.B.S., M.A.B., M.S.A., C.L.F.C., N.S.G.M.S.S., M.L.S.G.S., 
N.P.F., F.G.S., V.F.N., A.R.S., N.D.C.F., K.K.J.V., S.T.R. and M.H.D.F; supervision, L.G.L.; project administration, L.G.L. All authors have read and agreed to the published version of the manuscript. All authors have read and agreed to the published version of the manuscript.

Funding: This research received no external funding.

Institutional Review Board Statement: The study was conducted according to the guidelines of the Declaration of Helsinki and the study was approved by the Research Ethics Committee at School of Medicine of São José do Rio Preto (decision: 2,896,620; CAAE: 93476218.2.0000.5324) on September 15, 2018.

Informed Consent Statement: Informed consent was obtained from all subjects involved in the study.

Data Availability Statement: The datasets generated during the current study are not publicly available but are available from the corresponding author on reasonable request.

Conflicts of Interest: The authors declare no conflict of interest.

\section{References}

1. Silva, M.C.N.; Machado, M.H. Health and Work System: challenges for the Nursing in Brazil. Ciênc. saúde coletiva 2020, 25, 7-13. https://doi.org/10.1590/1413-81232020251.27572019

2. Brazil. Lei $n^{\circ} 7.498$, de 25 de junho de 1986. Dispõe sobre a regulamentação do exercício da enfermagem, e dá outras providências. Republic Presidency 2020. Available online: https:/www.planalto.gov.br/ccivil 03/leis/l7498.htm (accessed on 15 Jan 2022).

3. Santos, M.C.P. Mobilização da subjetividade de auxiliares e técnicos de enfermagem atuantes na linha de frente de combate à Covid-19: uma compreensão à luz da Psicodinâmica do trabalho. Master's Thesis, Federal University of Pernambuco, Recife, PE, Brazil, 2021.

4. World Health Organization. State of the world's nursing 2020: executive summary. World Health Organization, 2020. Available online: https://apps.who.int/iris/handle/10665/331673 (accessed on 15 Jan 2022).

5. Mendes, I.A.C.; Ventura, C.A.A. Nursing Protagonism in the UN Goals for the people's health. Rev. Lat.-Am. Enferm. 2017, 25, e2864. https://doi.org/10.1590/1518-8345.0000.2864

6. Conselho Federal de Enfermagem (BR). Enfermagem em números. COFEN, 2019. Available online: http://www.cofen.gov.br/enfermagem-em-numeros (accessed on 15 Jan 2022).

7. Machado, M.H.; Aguiar Filho, W.; Lacerda, W.F.; Oliveira, E.; Lemos, W.; Wermelinger, M.; Vieira, M.; Santos, M.R.; Souza Junior, P.B.; Justino, E.; Barbosa, C. Características gerais da enfermagem: o perfil sócio demográfico. Enferm. Foco 2016, 7, 9-14. https://doi.org/10.21675/2357-707X.2016.v7.nESP.686

8. Contreras, C.C.T. COVID-19 Pandemics: an opportunity to give Nursing global visibility. Rev Gaúcha Enferm. 2020, 41, e20200139. https://doi.org/10.1590/1983-1447.2020.20200139

9. Ames, M.; Salmond, E.; Holly, C.; Kamienski, M. Strategies that reduce compassion fatigue and increase compassion satisfaction in nurses: a systematic review protocol. JBI Database Syst. Rev. Implement. Rep. 2017, 15, 1800-1804. https://doi.org/10.11124/JBISRIR-2016-003142

10. Rocha, D.D.; Nascimento, E.C.; Raimundo, L.P.; Damasceno, A.M.B.; Bondim, H.F.F.B. Sentimentos vivenciados pelos profissionais de Enfermagem diante de morte em unidade de terapia intensiva neonatal. Mental 2017, 11, 546-560.

11. Moraes Filho, I.M.; Almeida, R.J. Occupational stress at work in nursing in Brazil: an integrative review. Rev Bras Promoç Saúde 2016, 29, 447-454. http://doi.org/10.5020/18061230.2016.p447 
12. Souza, C.G.V.M.; Benute, G.R.G.; Moretto, M.L.T.; Levin, A.S.S.; Assis, G.R.; Padoveze, M.C.; Lobo, R.D. Qualidade de vida profissional na saúde: um estudo em Unidades de Terapia Intensiva. Estud. psicol. (Natal) 2019, 24, $269-280$. http://dx.doi.org/10.22491/1678-4669.20190028

13. Rotta, D.S.; Pinto, M.H.; Lourenção, L.G.; Teixeira, P.R.; Gonsalez, E.G.; Gazetta, C.E. Anxiety and depression levels among multidisciplinary health residents. Rev Rene 2016, 17, 372-377. http://dx.doi.org/10.15253/2175-6783.2016000300010

14. Moreira, A.C.; Lourenção, L.G.; Sassaki, N.S.G.M.S.; Gazetta, C.E.; Vendramini, S.H.F.; Santos, M.L.S.G. Mortality risk associated with blood sugar levels in patients with septicemia in Intensive Care. Rev Rene 2016, 17, 324-329. http://dx.doi.org/10.15253/2175-6783.2016000300004

15. Julio, R.S.; Lourenção, L.G.; Penha, J.G.M.; Oliveira, A.M.N.; Nascimento, V.F.; Oliveira, S.M.; Gazetta, C.E. Anxiety, depression, and work engagement in Primary Health Care nursing professionals. Rev Rene 2021, 22 , e70762. http://dx.doi.org/10.15253/2175-6783.20212270762

16. Borges, E.M.N.; Fonseca, C.I.N.S.; Baptista, P.C.P.; Queirós, C.M.L.; Baldonedo-Mosteiro, M.; Mosteiro-Diaz, M.P. Compassion fatigue among nurses working on an adult emergency and urgent care unit. Rev. Lat.-Am. Enferm. 2019, 27, e3175. http://doi.org/10.1590/1518-8345.2973.3175 _

17. Pehlivan, T.; Güner, P. Compassion fatigue: The known and unknown. J Psychiatric Nurs 2018, 9, 129-134. http://doi.org/10.14744/phd.2017.25582

18. Cocker, F.; Joss, N. Compassion Fatigue among Healthcare, Emergency and Community Service Workers: A Systematic Review. Int. J. Environ. Res. Public Health 2016, 13, 618. http://doi.org/10.3390/ijerph13060618

19. Fabri, N.V.; Martins, J.T.; Galdino, M.J.Q.; Ribeiro, R.P.; Moreira, A.A.O.; Haddad, M.C.L.F. Satisfacción, fatiga por compasión y factores asociados en las enfermeras de la atención primaria . Enf Global 2021, 20, 291-323. https://doi.org/10.6018/eglobal.457511

20. Empresa Brasileira de Serviços Hospitalares. Available online: http://www.ebserh.gov.br/web/hu-furg/nossa-historia (accessed on 15 Jan 2022).

21. Lago, K.; Codo, W. Fadiga por compaixão: evidências de validade fatorial e consistência. Estud. psicol. (Natal) 2013, 18, 213-21. https://dx.doi.org/10.1590/S1413-294X2013000200006

22. Stamm, B.H. The Concise Manual for the Professional Quality of Life Scale, 3rd ed.; Ed. Pocatello: Idaho, USA, 2010. Available online: https://img1.wsimg.com/blobby/go/dfc1e1a0-a1db-4456-9391-18746725179b/downloads/ProQOL\%20Manual.pdf?ver= $\underline{1622839353725}$ (accessed on 15 Jan 2022).

23. Figueiredo Filho, D.B.; Silva Júnior, J.A. Desvendando os Mistérios do Coeficiente de Correlação de Pearson (r). Polít. Hoje 2009, 18, 115-146. Available online: https://periodicos.ufpe.br/revistas/politicahoje/article/viewFile/3852/3156 (accessed on 15 Jan 2022).

24. Oviedo, H.C.; Campo-Arias, A. Aproximación al uso del coeficiente alfa de Cronbach. Rev. colomb. psiquiatr. 2005, 34, 572-580. Available online: http://www.scielo.org.co/scielo.php?script=sci_arttext\&pid=S0034-74502005000400009\&lng=en (accessed on 15 Jan 2022).

25. Jarrad, R.; Hammad, S.; Shawashi, T.; Mahmoud, N. Compassion fatigue and substance use among nurses. Ann Gen Psychiatry 2018, 17, 13. http://dx.doi.org/10.1186/s12991-018-0183-5

26. Membrive-Jiménez, M.J.; Pradas-Hernández, L.; Suleiman-Martos, N.; Vargas-Román, K.; Cañadas-De la Fuente, G.A.; Gomez-Urquiza, J.L.; De la Fuente-Solana, E.I. Burnout in Nursing Managers: A Systematic Review and Meta-Analysis of Related Factors, Levels and Prevalence. Int. J. Environ. Res. Public Health $2020,17,3983$. https://doi.org/10.3390/ijerph17113983 
27. Cao, X.; Naruse, T. Effect of time pressure on the burnout of home-visiting nurses: The moderating role of relational coordination with nursing managers. Jpn. J. Nurs. Sci. 2018, 16, 221-231. https://doi.org/10.1111/jins.12233 28. Cordioli, D.F.C.; Cordioli Junior, J.R.; Gazzeta, C.E.; Silva, A.G.; Lourenção, L.G. Occupational stress and work engagement in primary health care workers. Rev Bras Enferm 2019, 72, 1580-1587. http://dx.doi.org/10.1590/0034-7167-2018-0681

29. Cordioli Junior, J.R.; Cordioli, D.F.C.; Gazetta, C.E.; Silva, A.G.; Lourenção, L.G. Quality of life and osteomuscular symptoms in workers of primary health care. Rev Bras Enferm 2020, 73, e20190054. http://dx.doi.org/10.1590/0034-7167-2019-0054

30. Karanikola, M.; Giannakopoulou, M.; Mpouzika, M.; Kaite, C. P.; Tsiaousis, G. Z.; Papathanassoglou, E. D. E. Dysfunctional psychological responses among Intensive Care Unit nurses: a systematic review of the literature. Rev Esc Enferm USP 2015, 49, 847-57. https://doi.org/10.1590/S0080-623420150000500020

31. Flanders, S.; Hampton, D.; Missi, P.; Ipsan, C.; Gruebbel, C. Effectiveness of a Staff Resilience Program in a Pediatric Intensive Care Unit. J. Pediatr. Nurs 2019, 50, 1-4. https://doi.org/10.1016/j.pedn.2019.10.007

32. Sorenson, C.; Bolick, B.; Wrigth, K.; Hamilton, R. Understanding Compassion Fatigue in Healthcare Providers: A Review of Current Literature. J. Nurs. Scholarsh 2016, 48, 456-465. https://doi.org/10.1111/jnu.12229

33. Beck, C.T.; Cusson, R.M.; Gable, R.K. Secondary traumatic stress in NICU nurses: a mixed-methods study. Adv. Neonatal Care 2017, 17, 478-488. http://doi.org/10.1097/ANC.0000000000000428

34. O'Callaghan, E.L.; Lam, L.; Cant, R.; Moss, C. Compassion satisfaction and compassion fatigue in Australian emergency nurses: A descriptive cross-sectional study. Int. Emerg. Nurs 2020, 48, 100785. https://doi.org/10.1016/j.ienj.2019.06.008

35. Wentzel, D.L.; Brysiewicz, P. A survey of compassion satisfaction, burnout and compassion fatigue in nurses practicing in three oncology departments in Durban, South Africa. Int. J. Afr. Nurs. Sci. 2018, 8, 82-86. https://doi.org/10.1016/j.ijans.2018.03.004

36. García, G.M.C.H. Fatiga por compasión entre profesionales sanitarios de oncología y cuidados paliativos. Psicooncologia 2017, 14, 53-60. https://doi.org/10.5209/PSIC.55811

37. Al Barmawi, M.A.; Subih, M.; Salameh, O.; Sayyah, N.S.Y.; Shoqirat, N.; Abu Jebbeh, R.A.A.E. Coping strategies as moderating factors to compassion fatigue among critical care nurses. Brain Behav 2019, 9, e01264. https://doi.org/10.1002/brb3.1264

38. Duarte, J. Professional quality of life in nurses: Contribution for the validation of the Portuguese version of the Professional Quality of Life Scale-5 (ProQOL-5). Anál. psicol. 2017, 4, 529-542. http://doi.org/10.14417/ap.1260

39. Ruiz-Fernández, M.D.; Pérez-García, E.; Ortega-Galán, Á.M. Quality of Life in Nursing Professionals: Burnout, Fatigue, and Compassion Satisfaction. Int J Environ Res Public Health 2020, 17, 1253. http://doi.org/10.3390/ijerph17041253

40. Dikmen, Y.; Aydın, Y.; Tabakoğlu, P. Compassion fatigue: A Study of critical care nurses in Turkey. Hum. Sciences 2016, 13, 2879-2884. http://dx.doi.org/10.14687/jhs.v13i2.3752

41. Wang, J., Okoli, C.T.C., He, H., Feng, F., Li, J., Zhuang, L., Lin, M. Factors Associated with Compassion Satisfaction, Burnout, and Secondary Traumatic Stress Among Chinese Nurses in Tertiary Hospitals: A Cross-Sectional Study. Int. J. Nurs. Stud. 2020, 102, 103472. https://doi.org/10.1016/j.ijnurstu.2019.103472 